\title{
AtUALIZAÇÃO NO TRATAMENTO DA DISFUNÇÃO ERÉTIL COM DROGAS INIBIDORAS DA FOSFODIESTERASE TIPO 5, BASEADA EM EVIDÊNCIA E CENTRADA NO PACIENTE \\ Sidney Glina, Wanderley Marques Bernardo
}

\section{TEMAABORDADO}

Especialidade de abrangência: Urologia.

Diretriz a ser consultada: Disfunção erétil: tratamento com drogas inibidoras da fosfodiesterase tipo 5

Cenários e Questões clínicas

I. Os inibidores da Fosfodiesterase tipo 5 (iF5) constituem hoje a terapia oral mais utilizada na disfunção erétil. Atuam promovendo:

a. Efeito no sistema nervoso central;

b. Efeito através do aumento dos níveis de testosterona;

c. Contratura da célula muscular do tecido cavernoso;

d. Relaxamento da célula muscular do tecido cavernoso

2. Entre os iF5 estão a Sildenafila, a Vardenafila e a Tadalafila. Os intervalos de início mínimo da atividade erétil e de sua duração máxima, com o uso dessas drogas, variam respectivamente em:

a. 60 minutos e 6 horas;

b. 12 minutos e 36 horas;

c. 15 minutos e 12 horas;

d. 24 horas e 60 minutos.

3. Todos os três medicamentos são seguros do ponto de vista cardiovascular. Qual a frase que não se adequa aos inibidores F5?

a. Não apresentam efeitos negativos sobre a função cardíaca;

b. Tendem a piorar o quadro clínico de pacientes com insuficiência coronariana estável;

c. As alterações encontradas no eletrocardiograma não foram consideradas significantes;

d. O uso de iF5 não aumentou a incidência de acidentes vasculares.

\section{Está entre os efeitos colaterais dos iF5:}

a. Congestão nasal;

b. Efeitos negativos sobre a função cardíaca;

c. Acidentes vasculares;

d. Alteração na motilidade dos espermatozóides.

5. É contra-indicação absoluta para o uso dos iF5 na disfunção erétil:

a. Uso concomitante com os alfabloqueadores;

b. Uso concomitante com anti-hipertensivos;

c. Uso concomitante com nitratos;

d. Uso concomitante com o cetoconazol.

\section{Respostas do Cenário Clínico "Diagnóstico da Hemorróida [Publicado na Ramb 2007; 53(2)]}

I. Podemos definir e classificar a doença hemorroidária de diversas formas, exceto quanto à anatomia, em prolapsada ou trombosada (alternativab);

2. O sangramento é sintoma da doença hemorroidária, e pode levarà anemia (alternativa c);

3. O exame digital é importante no diagnóstico da doença hemorroidária, e deverá ser evitado na vigência de lesões dolorosas (alternativaa);

4. Todos os pacientes com idade acima de 40 anos, com sangramento retal, devem ser submetidos à sigmoidoscopia flexível ou colonoscopia (alternativa d);

5. Em relação ao uso da colonoscopia no diagnóstico diferencial de sangramento retal, éfalso afirmar que, éinjustificada em indivíduos com idade inferior a 40 anos (alternativa a). 